Journal of Alternative \& Community Media

Volume 5 Number 1

(C) 2020 Intellect Ltd Article. English language. https://doi.org/10.1386/joacm_00072_1

Received 15 April 2018; Accepted I November 2018

FÉLIX TRÉGUER

National Centre for Scientific Research (CNRS)

DOMINIQUE TRUDEL

Audencia Business School

MÉLANIE DULONG DE ROSNAY

National Centre for Scientific Research (CNRS)

\title{
Learning from the history of alternative communication networks
}

\begin{abstract}
This article explores the legal, economic and governance challenges to the sustainability of contemporary alternative Community Networks by drawing lessons and parallels from eight historical precedents. Building on academic literature related to alternative and community media, the article lays out an encompassing definition of alternative networks (or 'alternets') and develops a multidisciplinary approach to comparative history. After briefly presenting eight case studies (three independent telephone networks of the late nineteenth century; three Free Radios of the 1950s, 1960s and 1970s; two Community Networks providing Internet access in the 1990s), the article then draws from these case studies to identify key recurring challenges that can inform present-day initiatives, namely, the articulation of local community with global connectivity, the development of political advocacy capacities aimed at influencing the law and technology, the creation of appropriate resources aimed at resisting co-optation, and the need to build collective cohesion and mechanisms to handle disagreements.
\end{abstract}

\section{KEYWORDS}

advocacy

alternative networks

commons

Community Networks

Free Radio

Internet

telecom regulation

telephone 
In recent years, there has been a growing interest in Community Networks, that is alternative telecommunications infrastructures deployed and maintained by local communities to serve their needs and build up their communication autonomy (Navarro et al. 2016). Offering a third way between public authorities and market-based providers of telecommunication services (e.g., Internet access provision), some of these initiatives, like Guifi.net in Spain or Freifunk in Germany, contribute to expanding the 'Internet commons' to the physical layer of the network (Benkler 2016; De Filippi and Tréguer 2015). Community Networks, therefore, represent a form of 'alternative Internet infrastructure' with the potential to challenge the political economy of the Internet, one marked by a growing concentration and commodification (McChesney 2013). But Community Networks are only seldom historicized on the longue durée, in the context of similar historical endeavours such as community telephony and radio. On the short-term time scale of event-driven history, the literature on Community Networks is also sparse (Tréguer and Trudel 2019). Scholars and practitioners concerned with the sustainability of these initiatives, therefore, miss out on some of the lessons that past alternative networks or'alternets' may offer.

Throughout the nineteenth and twentieth centuries, the telegraph, telephone, radio and television were also disruptive technologies. And as many scholars have shown, contemporary debates over the control of the Internet - issues of access, privacy and freedom of expression, oligopolization and neutrality - are reminiscent of older political conflicts over the development of these pre-digital communication technologies (Wu 2010; Pickard 2013, 2015a). In different ways, these technologies saw the advent of 'alternative networks' built to resist hegemonic models. To do so, they developed strategic action repertoires and cultural-ideological frames, explored alternative technological designs or organizational strategies with the goal of transforming their cultural, political and legal environment.

In this article, we seek to explore the history of these alternative communication networks to inform the action of contemporary community-based networks. Our hope is that through the lens of history, contemporary issues and challenges surrounding Community Networks may benefit from new insights and appear in clearer terms. To do so, we begin by laying out definitions of alternative communication networks by drawing on existing literature. Taking inspiration from various traditions of communication history, we propose an original, multidisciplinary approach to embarking in this form of comparative history concerned with today's struggles for emancipation in the media and telecommunication fields. After briefly presenting the eight case studies (fully developed in a research report from which this article is adapted, see Trudel and Tréguer 2016), we move to the lessons learned and identify four overlapping challenges for the sustainability of alternative networks. Of course, such exercise is risky business: if communication technologies are shaped by their environment, it necessarily implies that all case studies are somehow unique as they belong to very specific contexts. In this sense, all parallels we can offer are nothing much more than parallels as the past and the present never quite coincide. French historian Nicole Loraux (2005: 135) advocates for a 'reasoned used of anachronism', emphasizing that, when working in a regime of anachronism, there is much 'to be learned from the process of returning to the present'. In that spirit, and while remaining wary of the risk of overemphasizing historical continuity, we seek to enlighten present stakes by drawing lessons from the past. As argued by Pickard, the emerging 
media reform movement can learn useful lessons from past reform movements, as 'history can provide guidance and help steer this new movement away from past mistakes' (2015b: 124).

\section{DEFINING 'ALTERNATIVENESS' IN COMMUNICATION NETWORKS}

First published in 1970, Enzensberger's Constituents of a Theory of the Media provides a useful starting point for conceptualizing alternative communication networks. Enzensberger (2003) proposed a typology of the 'repressive' and 'emancipatory' use of media that echoes contemporary discourses about the emancipatory potential of Community Networks. While the repressive uses of the media reflect and are characterized by centralization, unidirectional communication, depoliticization, and the control exercised by specialists and bureaucrats, emancipatory uses are associated with and supported by decentralization, multidirectional communication, political mobilization and self-organization.

This typology raises interesting questions. The opposition between repressive and emancipatory uses may be too sharp to grasp the multiplicity of uses and their political dimensions. For example, one may argue that all media are characterized by minimal forms of specialized work and politicization processes. Enzensberger also implies that all broadcasting media (one-tomany transmission) such as radio and television are inherently repressive. Conversely, many emancipatory uses mentioned by Enzensberger (decentralization, multidirectional communication, self-organization) are general characteristics of the original Internet, which is also partially controlled by powerful state and private actors.

Although useful, Enzensberger's typology must be considered with care in order to grasp the dialectical relations between repressive and emancipatory uses of media. In other words, rather than identifying predetermined characteristics of alternative and mainstream media, we should fully embrace the complex dimensions of 'alternativeness' throughout history in order to reconstruct different iterations of alternative media and networks as commons. We should also consider centralization and unidirectionality not as a technical fate or choice of design, but rather a social construct resulting from contingent governance models, for which alternatives are possible (Dulong de Rosnay and Musiani 2016).

Recent scholarly discussions on media alternativeness focus on the specific context of the Internet. Preston (2001: 209), for instance, notes that alternative Internets were found in online applications that'manage to challenge and resist domination by commercial and other sectional interests', in particular those 'operating as alternative and/or minority media for the exchanges of news and commentary on political and social developments which are marginalised in mainstream media and debates'. In similar ways, Fuchs (2010) argues that alternative media are 'critical media' that questions domination and expresses the standpoint of oppressed groups or individuals. For Sandoval and Fuchs (2010), the defining characteristic of alternative media is to contribute to emancipatory social transformation. In a different manner, Atton (2005) writes that alternative online media are'produced outside the forces of market economics and the state' (2005: 3). In these definitions, alternativeness is measured in distance from the centres of state and capital (Tréguer et al. 2016).

Adopting a broader perspective, Bailey et al. (2008) situate alternative media 'in relation to mainstream media; as embedded in the citizenship 
politics of civil society; as a means for self-representation by communities, and as a hybrid form of independent media challenging established relations of authority and control' (2007: x). Couldry (2015) defines alternative media with regard to voice, understood as

the expression of opinion, or, more broadly, the expression of a distinctive perspective on the world that a political system could acknowledge [...] voice being the value that motivates the production of alternative media $[\ldots]$ the possibility to be listened to.

These competing definitions may be complemented by Cardon and Granjon's (2010) distinction between 'expressive criticism' and 'anti-hegemonic criticism'. While some alternative media are defined by their mission of giving voices to marginalized groups (what the authors call 'expressive criticism'), other are characterized by their critique of mainstream capitalist media ('antihegemonic criticism').

Following up on these different definitions, we posit that alternativeness is best understood through examination of many different dimensions, such as the funding and economic models, the governance schemes and decisionmaking mechanisms, the underlying content and, most crucially, the political values that it circulates, enables or that is embedded within it. In this sense, there are no strict boundaries between alternative and non-alternative media. For example, at least some of the so-called mainstream media tend to criticize (at least some aspects of) neo-liberal politics or give voice to oppressed or under-represented groups. But does it suffice to make them 'alternative media', even if they are controlled by capitalist corporations and can arguably be counted as guardians of political orthodoxies and of the existing power balance? Of course not.

The same can be said of alternative media which, to varying degrees, are articulating dialectical contradictions. In that spirit, Sandoval and Fuchs (2010: 147) have argued for'politically effective alternative media that in order to advance transformative political can include certain elements of capitalist mass media'. According to them, subscription fees or even advertising might be necessary to reach a broader audience and gain political efficacy. In other words, 'alternative' is not a substantial quality of a given media or network but a useful starting point to identify a wide range of heterodox discourses and practices aimed at (re)constructing communication technologies as a vehicle for emancipatory politics.

A final theoretical distinction to be made is that between 'alternative media' and 'alternative networks'. Although both terms largely depict the same reality, 'networks' refers to the physical and distributed infrastructure of communication, whereas 'media' inevitably evokes centralized 'mass media', that is a specific socio-technical assemblage making use of that infrastructure. In speaking of alternative networks, we thus aim to expand critical reflections about alternative media to communication infrastructure and their political economy. It is also an attempt to connect our own work and the scholarship on alternative media and their sustainability to the also alternative production and governance model of the commons - in particular to the emerging studies on 'infrastructure as a commons' (Frischmann 2007) - while remaining bound to the rich tradition of alternative media scholarship and to its focus on the critical function of alternative media. 


\section{A MULTIDISCIPLINARY PERSPECTIVE}

Approached from a multidisciplinary perspective, the analysis of eight case studies selected in this article (three community telephone networks of the late nineteenth century, three Free Radio stations of the 1960s and 1970s, two Community Networks providing Internet access in the 1990s) takes place at the intersection of five different fields of inquiry and proposes a specific contribution to each of these fields.

First, our approach inherits from the historical sociology of social movements. We conceptualize contemporary Community Networks as forms of social movements to the extent that these collectives are made up of actors characterized by a 'set of opinions and beliefs in a population which represents preferences for changing some elements of the social structure and/ or reward distribution of a society' (McCarthy and Zald 1977: 1217-18). In a slightly different way, Tilly and Tarrow (2015) emphasize the collective political action and practices undertaken by social movements, defined as 'a sustained campaign of claim-making, using repeated performances that advertise the claim, based on organisations, networks, traditions, and solidarities that sustain these activities' (2015: 8). Drawing from these definitions, we seek to study the mutations over time of these movements in constantly shifting contexts. As Deflem and Lee Dove (2013) remark, 'historical sociology is not a mere study of the past, but an intrinsic part of a sociology of the present: in order to explain the structures of contemporary societies, one must investigate their historical origins and development' (2013: 293). For this article, the complex co-shaping of alternative networks, communications technologies and communications law specifically concerns us. Historical comparative analysis is especially suited to our goals since it is defined by a concern with causal analysis, an emphasis on processes over time, and the use of systematic and contextualised comparison' (Mahoney and Rueschemeyer 2003: 6).

Second, our approach is grounded in the field of media history. Like most fields of historical inquiry, media history focuses on dominant actors and mainstream uses, while the history of struggles over new technologies still remains largely to be written (see Pickard 2015b). However, various historiographical streams have sought to move away from canonical narratives. In the late 1980s and early 1990s, social history of media began to describe the complex co-shaping of technologies, politics and culture. More recently, Acland's (2006) inquiry into 'residual media' has sought to uncover experiences, meanings and values that are latent in contemporary media cultures and that can potentially be reactivated by means of history. By looking at these latent pasts and to the complex co-shaping processes, our research aims to further develop such historical perspectives showing that even prior to the Internet, communications infrastructure already operated as 'sites of cultural contestation' (MacKenzie 2005: 269).

Third, this analysis is informed by the political history of the Internet. Moving away from single-sided narratives that have achieved iconic status studies focusing on a handful of over-quoted contentious episodes and generally over-representing North America, or scattered accounts that have so far escaped the notice of Internet researchers (see Tréguer 2017) - we aim to move away from US-centric scholarship to make both cross-temporal and crossnational comparisons. In doing so, we try to break away from the persisting myth of the Internet's radical 'newness'. 
Fourth, our perspective inherits from the history and the governance of the commons. In Das Kapital, Karl Marx described with great attention the enclosures of the commons in England. Marx's works inaugurated a stream of historiography that was further developed by Marxist historians such as E. P. Thompson and Christopher Hill and, more recently, by Derek Wall (2014). These historians rejected the narrative of the 'tragedy of the commons' according to which commons necessarily fail because of the so-called 'free riders' taking advantage of the shared resource (Hardin 1968). Rather, for these authors, the destruction of the commons was 'a key stage in the creation of a market-based social system' (Wall 2014: 13). Our contribution to the history of the commons also pays attention to the history of communication technologies and inscribed it in the history of information and knowledge commons (Hess and Ostrom 2007), which have been subject to forms of commodification that have led to a'second enclosure movement' (Boyle 2003).

Lastly, our approach inherits from scholarship coming from the field of science and technology studies. In this field, the social construction of technology developed as a conceptual framework to understand how technologies and media are shaped by numerous actors and their practices (Bijker et al. 1987). Adopting such a perspective, our case studies give equal attention to technical, social, political, economic and legal factors that are shaping emerging communication technologies. We were specifically interested in exploring the so-called 'phases of interpretative flexibility' (Bijker et al. 1987) during which different groups are adopting competing technological designs and practices.

\section{CHOICE OF CASE STUDIES}

Our research investigates three different communication technologies and models of communication: the telephone (point-to-point communication), the radio (one-to-many communication) and the early alternative Internet access providers (many-to-many communication). For each of them, we surveyed historical episodes during which actors tried to challenge the stronghold of state or market actors at moments when the future of the technology still seemed open. Presented in more detail in our research report (Trudel and Tréguer 2016), our case studies focus on three independent telephone networks at the turn of the nineteenth century and on the specific challenges they faced. In the American Midwest, independent telephone networks faced the rising hegemony of AT\&T. In Sweden, the telephone cooperatives faced the monopoly of the State over long-distance lines. In France, local governments and local business communities enjoyed a large degree of autonomy in developing the telephone before turning over the network to the Ministry of Post and Telegraph. For alternative radio networks, we looked at the case of Radio Pacifica in the United States, created in 1946 and originally anchored in the Pacifist movement. We then moved to the British pirate radios of the 1960s and to the French Free Radio movement of the late 1970s, which both challenged the state's monopoly over broadcasting. Our last two case studies get ever closer to the present by looking at two Community Networks that appeared in the 1990s. Founded in 1992 and still active, the French Data Network (FDN) was the first Internet access provider available to the general public and played a key role in defining French Internet activism. Founded in 1999, Consume.net was tied to the London counter-cultural scene and took advantage of the apparition of Wi-Fi protocols to subvert incumbent telecom operators' hold on the 'last-mile' of networks. 
One may ask, why study the telephone, radio and citizen Internet networks instead of other media technologies, such as the telegraph and the newspaper? Why focus on a country or a case rather than another? These are important questions to answer.

The telephone industry is probably the paradigmatic example of the development of communication networks during the twentieth century. In the United States, the cinema, radio and television industries all modelled themselves on Bell and AT\&T (Wu 2010). Following that model, they became centralized industries with monopolistic tendencies, and they were helped by the state all along this process. In this respect, the struggle opposing Bell/ AT\&T and the independent Community Networks exemplifies some aspects of the struggles that were fought throughout the twentieth century by other forms of alternative media and networks. Another reason to study the telephone is the profound similitude between telephone networks and today's Internet. Both are communication technologies that enable interpersonal communications, allowing 'co-presence'. In this sense, they are much more alike than broadcasting technologies like radio and television.

The Free Radio movement is quite a different business. Unlike the struggles over the telephone, the Free Radio movement had a transnational component. In Europe, pirate radios were broadcasting simultaneously to various national audiences. They influenced one another and collaborated on several occasions, including through the Fédération Européenne des Radios Libres, established in 1986. Consequently, they were repressed with new transnational legal instruments such as the European Agreement for the Prevention of Broadcasts Transmitted from Stations Outside National Territories of 1965. As an international social movement, Free Radio is interesting because it echoes today's global networked struggles over issues such as Net neutrality as well as the transnational coordination of Community Networks (Tréguer and Dulong de Rosnay 2018). Also noteworthy is the fact that the Free Radio movement was connected to larger movements of media criticism and media activism (Brinson 2006). It cannot be separated from new forms of discourse and knowledge, including forms of policy advocacy, political activism and media criticism that were fuelled by academic research and that can be traced back to the post-war radio reform movement (see Pickard 2013). For example, the founders of Radio Pacifica were influenced by the work of Charles Siepmann, one of the most important radio scholar and reformer of the postwar years (Lasar 1999). This echoes contemporary struggles with their forms of cross-fertilization between Community Networks, researchers and advocacy groups focused on defending digital rights and/or information and knowledge commons (Tréguer and Dulong de Rosnay 2018).

Finally, the early Community Networks providing Internet access that developed in the 1990s and early 2000s are the historical matrix and the first experiments leading to today's Community Networks. Most of them did not survive (or were radically challenged and transformed by) the rise of the commercial Internet service providers in the mid-1990s. Unlike the case studies on the early independent telephone networks and Free Radio movement, which were based on existing historiography, our analysis of FDN and Consume.net is mostly based on interviews and primary sources (see also Tréguer and Trudel 2019). Our work, therefore, contributes to the historiography of the Internet and of community media, which has so far overlooked these actors, one important exception being the late Medosch's (2014) 
unpublished history of early Wireless Community Networks, The Rise of the Network Commons.

Another guiding principle consisted in selecting cases that differed from each other, in order to better account for the diversity of alternative and Community Networks. For example, as many historians pointed out to the similarities between the Italian and French Free Radio movements - the Italian case representing the 'prototype of a new problem' (Raboy 1993: 132) - we decided to study only one of them. A further criterion was the historical significance of the case: Did this episode had enduring effects? Did it inspire others or marked a breaking point, a 'critical juncture' in the political economy of the media (McChesney 2007: 10)? A last concern was the heuristic and pedagogical value of the case studies to reflect on issues faced by today's Community Networks.

\section{METHODOLOGY}

Once our case studies selected, we identified and read carefully the relevant literature or, alternatively, interviewed key actors involved in setting up Community Networks in the 1990s (see Table 1 or Trudel and Tréguer 2016 for a detailed account of the bibliographical sources). We approached these writings and these interviews with four sets of loosely defined intertwined questions, as we looked for both transversal patterns and singularities. These questions benefited from an iterative research process that took the form of a cross-reading of the historical literature about our cases studies and of the recent works about Community Networks. First, we looked at the specific repertoire of strategic actions employed by these alternets and on their effects. Second, we focused on the co-shaping of technologies and the political/ legal environment, as we were concerned by the capacity of these alternets to change their cultural, legal and political environment. Third, we turned to the relations of these alternets with state and market actors, and on the various forms of co-optation they faced and try to resist. Fourth, we revisited the cases looking for implicit or explicit concerns to the commons (or other related concepts). Drawing from the various answers to these questions, we were able to identify four challenges regarding the sustainability of contemporary Community Networks.

\section{CHALLENGE \#1: ARTICULATING THE LOCAL AND THE GLOBAL}

A first challenge that can be identified from our journey in the history of alternative networks is tied to tensions between the local, national and global geographies of alternative networks. In the late nineteenth century, for the American Independent telephone companies, the telephone became not only a medium for peer-to-peer communication but also a civic media - what Carey (1989: 147) called 'an extended town meeting' - contributing to the social conversation in a world thought to be increasingly atomized. But the ability to establish long-distance links interconnecting local networks quickly became a necessity to make these initiatives sustainable. The US telephone independents' failure to cooperate to build long-distance networks eventually weakened their utility and enabled AT\&T to frame itself as a legitimate hegemon in order to realize the full potential of the telephone (Gabel 1969). In France, the original compromise made by local telephone networks with the central state to ensure national and international connectivity eventually 


\begin{tabular}{|c|c|}
\hline Case studies & Main historical sources \\
\hline $\begin{array}{l}\text { Independent Telephone } \\
\text { Networks, the United States } \\
(1893-1907)\end{array}$ & $\begin{array}{l}\text { Atwood (1984); Beauchamp (2015); Casson (1910); Gabel (1969); } \\
\text { Holcombe (1911); John (2010); Latzke (1906); Fischer (1992); } \\
\text { MacDougall (2014, 2015) }\end{array}$ \\
\hline $\begin{array}{l}\text { Cooperative Telephone Networks, } \\
\text { Sweden (1883-1910) }\end{array}$ & $\begin{array}{l}\text { Bennett (1895); Bonow (1938); Brault (1888); Holcombe (1911); } \\
\text { Huurdeman (2003); Kaijser (1987); Webb and Cox (1911) }\end{array}$ \\
\hline $\begin{array}{l}\text { Municipal Telephone Networks, } \\
\text { France (1888-99) }\end{array}$ & $\begin{array}{l}\text { Aulas (1999); Bennett (1895); Bertho and Carré (1994); Holcombe } \\
\text { (1911); Leroux (1991); Webb and Cox (1911) }\end{array}$ \\
\hline $\begin{array}{l}\text { Radio Pacifica, the United States } \\
\text { (1946-present) }\end{array}$ & Land (1999); Lasar (1999); 2015; Walker (2001) \\
\hline $\begin{array}{l}\text { Radio Caroline, the United } \\
\text { Kingdom (1964-80) }\end{array}$ & Chapman (1990); Johns (2011); Lesueur (2011); Robertson (1982) \\
\hline Radio Verte, France (1977-82) & $\begin{array}{l}\text { Bénetière and Soncin (1989); Lefebvre (2011); Lesueur (2011); } \\
\text { Méadel (1994); Ulmann-Mauriat (2000) }\end{array}$ \\
\hline $\begin{array}{l}\text { French Data Network, France } \\
\text { (1992-present) }\end{array}$ & $\begin{array}{l}\text { Bayart (interview); Chemla (interview) Nicaise (interview); Paulus } \\
\text { (interview) }\end{array}$ \\
\hline $\begin{array}{l}\text { Consume.net, the United } \\
\text { Kingdom (1999-2003) }\end{array}$ & Stevens (interview); Medosch (2014); Priest (2016) \\
\hline
\end{tabular}

Table 1: Overview of the cases studies and main historical sources.

led the latter to recentralize the network around Paris, rather than developing connectivity around regional urban centres. Swedish cooperatives initially fared much better, setting up appropriate coordination mechanisms between them (Kaijser 1987). But as we will see, their aspiration for interconnection would also seal their fate.

These tensions regarding to the local and the global were creatively dealt with by Consume.net at the turn of the 1990s, when it brought a major innovation to Internet politics by going against the globalizing tide. Whereas the first motivation of FDN had been to bring global connectivity to French tech-savvy people - one which for some time at least made it vulnerable to turning into a for-profit venture - Consume.net's activists wanted to make a claim, as they saw the Internet being fast-moulded into the macro-economic structures of global capitalism. The alternative, then, would be to conceptualize Internet-like networks organized by local communities. Sure, Consume. net's activists were aware of the fact that they needed to be connected to the global Internet to maintain relevance. But unlike the Independents of early telephone networks in the United States, long-distance interconnection was a feature widely available, and in their specific historical context, it was one they sought to counter-balance. To do so, they experimented new online media forms emerging from local communities, helping them to find their own voice and mediate it through online media, much like Free Radio had done a quarter-century earlier. The irony was that such initiative was made possible by a technical innovation - Wi-Fi brought about by the International Telecommunications Union, an international and corporate-friendly organization, and was first made available to the general public with the launch of Apple's Airport device. But that irony made the initiative all the more subversive: In allowing them to bypass the last-mile networks of corporate telecom providers, Wi-Fi could almost be framed as the manifestation of capitalism's 
self-destructive impulse (the ambivalence also reflected in the polysemic name of the initiative). But Consume.net's approach had a much more pragmatic component: like for FDN in its early days, taking part in the global Internet was costly. Sharing costs was a way of making it more affordable, and both FDN and Consume.net understood that the more the participants joined, the cheaper the community's total bandwidth costs would be.

Consume.net also sought for creative ways of bridging the local and the global. As MacKenzie (2005: 281) noted, Consumet.net was key in early attempts to 'engineer the connection of local networks into extensive ad hoc informal meshes of wireless nodes across local and national boundaries'. That joint effort took the form of the Pico Peering Agreement (PPA), a document first presented in 2003 which aimed to safeguard the values of privacy, neutrality and openness promoted by Consume.net and the then growing movement around Wireless Community Networks. The PPA held the potential of creating a network of Community Networks that would represent'a viable and competitive supplement to the Internet, but one where the system of ownership is decentralised enough for it to remain a common' (Alberts cited in MacKenzie 2005: 281).

The original idea of a Peering Agreement that would allow local Community Networks to federate at the national and transnational levels lives up to this day, but mostly under the form of experiments Community Networks usually prefer to send out their traffic to global networks through traditional telecom operators. But in the face of possible 'kill switches' where these corporate actors could decide to disconnect the community from global networks, the PPA still points to a possible workaround ensuring the resiliency of alternative networks, and a way to gain full autonomy in articulating the local and the global.

\section{CHALLENGE \#2: ORGANIZING A POLITICAL DEFENCE THROUGH LAW AND TECHNOLOGY}

Reviewing the history of alternative networks points to the importance of the co-shaping of law and technology for the fate and the design of alternative networks. As argued by Lessig (1999), these two different forms of 'code' legal and technological - create and constrain the affordances of communication networks. In many cases, the normative power of law and technology interpenetrated to open (or foreclose) a path for alternative networks. For example, the case of early telephone networks shows the importance of patents (or their absence) in hindering (or providing) small alternative players' access to key technologies and shaping of telecommunications markets. In the United States, AT\&T's early twentieth century claim that the telephone was a 'natural monopoly' would not have been so convincing without Bell's first monopoly (1876-93), based on Bell's patents. The case of Sweden also proves the importance of patent laws over the development of telecommunications. The development of the Swedish telephone industry, including the key role played by the cooperatives, was to a certain extent shaped by the absence of Bell's patents. Thanks to the absence of intellectual property or legal enclosure, the field was open to unexpected technical choices and alternative players.

In the early 1970s, the end of the state monopoly over broadcasting in Italy led to a strong demand for radio broadcasting equipment, which, in turn, made such equipment available to activist groups based in France and fuelled a movement that would eventually end the state monopoly there 
too. Later, the Free Radio movement would, however, become marginalized through legal reforms leading to licensing schemes that systematically favoured commercial players over grassroots groups (Lefebvre 2011). In the 1990s, the International Telecommunications Union decision to open up Wi-Fi frequencies to unlicensed use led to the introduction of new radio devices that allowed for significant changes in the political economy of last-mile networks, sparking the so-called Wi-Fi revolution that gave birth to the first Wireless Community Networks. Today, regulations like the 2014 European directive on radio equipment change the liability regime for equipment providers and endanger the freedom of Community Networks to install new software on these devices and serve their specific needs and values, therefore their technolegal sustainability (Tréguer and Dulong de Rosnay 2018).

Sometimes, technology can also act as a substitute to the law, or a way to force changes to the regulatory framework. For example, in Sweden, a'technological ruse' used by the Telegraph Board (rather than strict regulation) eventually put an end to the movement. While the cooperatives were mostly using single-wire systems, the Telegraph Board strategically decided to interconnect only the networks using a double-wire system, although the two systems were technically compatible. The Telegraph Board accepted to finance the transition of local networks to double-wire system on the condition that it was given the opportunity to buy the networks. Fearing isolation, the cooperative companies accepted the trade-off one after the other. According to Kaijser (1987: 12), the subscriber's desire to be able to make interurban calls was stronger than their desire to own their telephone networks'. In 1907, there were only seventeen surviving cooperative telephone companies - fourteen of them located in rural areas - connecting only 971 telephones (Holcombe 1911). Three years later, the cooperatives had all been absorbed by the state telephone system or by its private rival, Allmänna Telefonaktiebolag.

In other cases, technology allows to circumvent the law altogether, or make it obsolete. Pirate and free radio stations used radio to subvert the state monopoly from international waters or terrestrial hideouts. In 1984, the Telecommunications Act (UK) banned the roll-out of landline infrastructure on the public realm. But Wi-Fi technology did not require physical access and could be used to bypass the tedious conditions and procedures required to roll out physical infrastructure, circumventing the practical chilling effects of the new legislation. In other words, technology might be used to exploit some of the cracks of the legal system or serve as a way to escape it altogether.

These general remarks point to the fact that law and technology are the 'master regulators' of alternative networks. Law appears to be the most important because it can mandate technological change, but technology is the primary driver as it is out of practical feasibility and economic convenience that alternative networks can emerge. According to these observations, Community Networks should self-organize to establish and maintain reflexive strategies than can help them influence technological and legal developments.

\section{CHALLENGE \#3: RESISTING CO-OPTATION THROUGH ECONOMIC SUSTAINABILITY}

This last point leads to another insight, namely, the fact that alternative networks are likely to be co-opted by market actors or the state. Again, and again, we have seen alternative networks or some of their key players being swallowed up by the very actors, structures or economic logic they were 
serving as an alternative for. Co-optation can take many forms. The first US independents that sold out to AT\&T weakened the whole movement and provided further justifications for lawmakers to sanction what was becoming AT\&T's de facto monopoly. Local telephone authorities in France were from the start ready to devolve their telephone networks to the state, but they eventually found out that the later performed poorly in maintaining and expanding these networks and that co-optation by central authorities came with important drawbacks. For the British Radio Caroline, as soon as the BBC launched new channels, the former star hosts of the pirate stations effectively moved to working for the state. The 'self-co-optation' of many of Consume.net's participants, who left to work in the tech industry, also suggests that when volunteer based, a network commons will often be difficult to sustain in the long run.

Our case studies suggest a possible counter-strategy that consists in establishing partnerships with well-established actors. Here, local authorities appear particularly important. In early US telephone networks for instance, local governments were hostile to Bell's monopoly and did use their powers to the independent's advantage. The strategy only failed when AT\&T successfully teamed up with the federal government and was granted the right to buy its competitors and strengthen what many state officials thought to be a'natural monopoly'.

In her study of Île Sans Fil, a Montreal-based community Internet provider, Powell (2008: 1069) describes how the establishment of a partnership between the city and Île Sans Fil constituted a turning point as it provided 'sustainable funding and a more conventional organisational structure'. Getting the support of public authorities may offer interesting assemblage between the 'public service' logic that the latter are supposed to embody, and the citizenowned and governed nature of the commons. Building such'public-commons partnerships' between commons-based networks and a 'partner state' (Kostakis and Bauwens 2014) points to the challenge to overcome the latent and often justified - distrust of many alternative networks actors towards state authorities and institutional politics.

Other potential solutions consist in fostering alliances between alternets and local professionals and businesses. Of course, this can be done out of shared, disinterested values: FDN and other more recent Community Networks rely on the volunteer labour and generosity of some of their active participants, some of which are connected to small- and mediumsized businesses that offer material and technical support. But governance frameworks can be designed in a way that creates an incentive for businesses to grow alternets. This was key in France's early local telephone networks, where local businessmen partnered with local authorities to find innovative funding schemes. Here again, Guifi has already proved very innovative, building local partnerships with both private and public entities, leveraging taxpayers' support as well as business incentives to grow the telecom commons (Navarro et al. 2016). These alliances with businesses might be controversial, but not only can they bring key resources to alternative networks; they can also help them spread their values within the commercial realm. Through such partnerships, Consume.net might have been able to grow along with the adoption of Wi-Fi hotspots by local businesses (like restaurants), grow stronger, and eventually pre-empt the instance of 'commons-washing' represented by telecom providers' commercial hotspots, like BT's 'Openzone'. 


\section{CHALLENGE \#4: BUILDING COLLECTIVE COHESION}

Though often operating at a macro scale, some of our case studies point to the ideological diversity of alternative networks, as well as to the various relationships and strategies of their participants with regard to the political sphere and the action repertoires developed to influence them. Milan (2013) provides an interesting typology to understand these varying approaches to politics in her analysis of emancipatory communication practices: (1) Beyonders acknowledge the failure of dominant institutions to answer their needs, and prefer to remain beyond the political system by focusing on the building of self-organized, decentralized and citizen-owned communications networks; (2) Outsiders pressure both regulators and incumbents from outside the political system, by means of protests, demonstrations and other campaigning tactics aimed at voicing dissent against the practices of commercial Internet access providers and against the lack of appropriate regulation for Community Networks; and (3) Insiders interact with public officials and regulators in order to make them support the deployment of Community Networks. This approach calls for the development and use of capacities for advocacy and mobilization, and the willingness to enter into negotiations with power-holders.

Our case studies suggest that alternative networks typically start as initiatives developing Beyonder strategies, taking the matter into their own hands to meet their need for communications. When the context turns more hostile, for instance when market and state actors coalesce to hinder their development or repress them, they develop oppositional strategies aimed at resisting this trend (legally and technically) and, in such context, generally manage to overcome their political differences.

The hardest part is to maintain some degree of cohesion when alternative networks need to articulate a positive agenda to policy-makers. In France, the Free Radio movement followed this trajectory. After the opening of the first stations, the government sought to crack down on this burst of free radio expression which contravened the government's exclusive right to public broadcasting. TéléDiffusion de France (TDF) sued several free radios in courts and sought to jam their transmissions. And as is often the case in the history of communications and other emancipatory struggles, repression led to technical and legal resistance. In Fessenheim, Alsace, a local Radio Verte was launched in June 1977. After having coped with several jamming attempts and successfully escaped a police arrest in the middle of a broadcast, the struggle became truly technical. As a Radio Verte activist explained,

our only possible reaction was to have a deeper penetration in all the layers of the population [...], to multiply the number of transmission sites so as to be even more powerful than TDF. Our strategy was to oppose decentralization to the centralism of the monopoly.

(Lefebvre 2011: 139)

The movement quickly organized full-fledged legal strategies. In September 1977, some of its most active members created the Association pour la Libération des Ondes (ALO), which benefited from the support of prominent intellectuals, including Gilles Deleuze, Félix Guattari and Umberto Eco (Lefebvre 2011). The organization was meant to coordinate the political and legal defence of the emerging movement while coordinating with their counterparts elsewhere in Europe. In 1978, they fought the French government's bill 
aimed at boosting the repression of the movement through petitions, manifestos, court challenges or drafted alternative bills that met their demands. But the movement's bill was aligned with the self-proclaimed 'pragmatist' side of the Free Radio movement opened to advertising, which alienated those who opposed commercialism and more generally represented an important cause of disagreement and fragmentation within the movement (Félix Guattari, for one, left the ALO over its acceptance of advertising to create the Fédération Nationale des Radios Libres). As elsewhere in Europe, the various reforms of the audio-visual sector adopted in the 1980s launched a wave of commercialization and concentration (Hesmondhalgh 2007). The state monopoly had fallen, but a new public-private hybridization would succeed in making the subversive agenda pushed by many in the Free Radio movement a marginal though vocal component of the French media landscape.

Divergence regarding the relation to market actors and resort to commercial-like models is also likely to be controversial for today's Community Networks, which have different political approaches to commoning. Papadimitropoulos (2017) sees three major political currents supporting the commons: the liberals, who anchor their defence of the commons through liberal theory and as middle-way between the state and the market; the reformists, who argue for the gradual adjustment of capitalism to the commons with the aid of a 'partner state'; and finally, the radical anti-capitalists who favour the commons 'against and beyond' capitalism. According to him (2017: 563), if the defenders of the commons are to overcome their contradictions and build solidarity despite their differences, 'a global institutional reform, followed by a number of inter-local and international principles, is sine qua non'. His point further stresses the need for building forms of political organization that can turn Community Networks into an actual social movement, with some degree of coordination, a common agenda and mechanisms to handle political disagreements - or at least push them aside when confronting institutions. The temporary synergies between Consume. net, marked by an anarchist ethos, with the 'reformist' group Campaign for Unmetered Telecommunications - which focused on getting lower prices and unlimited offers in commercial broadband - demonstrate that these can be quite effective: They successfully pre-empted BT's attempt to get lawmakers to outlaw Consume.net by extending the 1984 rule regulating the deployment of wired lines across the public realm to wireless transmission.

\section{CONCLUSION}

Grounded on the analysis of eight precedents of alternative networks, this article has sought to contribute to a definition of alternative communication networks, while identifying several common challenges they face in terms of sustainability. First, alternative networks will always have to manage the tension between the localities they are grounded in and whose needs they should serve and the global connectivity they will most often need to provide to their constituents. Our cases suggest that such global reach will likely rely on large corporations whose values are often at odds with those of alternative networks. Strategies are needed to foster the autonomy and resiliency of Community Networks and decrease this dependence. In this regard, following the pioneering experiments related to the PPA, interconnecting Community Networks transnationally appears to be an important task. Second, alternative networks activists and scholars should be aware that legal regulation and 
technological design are co-shaped and co-shaping affordances and services. Community Networks should self-organize to establish and maintain reflexive strategies than can help them influence technological and legal developments. Policy-makers can support the sustainability of these alternatives by making sure to invite them at the table of telecommunications policy reform discussions. Third, there is no single solution to avoid co-optation and ensure economic sustainability. Our case studies suggest that public-commons and private-commons partnerships are valuable options to ensure resilience. Fourth, building up the legal and political defence of alternative networks is an important task. The coordination of Community Networks' actions in the policy field can indeed help tackle big structural issues hampering their growth. Although such coordination needs to account for their diversity to avoid division, alternative networks should establish alliances with advocacy and research organizations with the goal of warding off the forms of collusion diverting telecommunications and media policies from the public interest.

Of course, these are just a few possible lessons that can inform today's activists, researchers and advocates working on alternative networks. More comparative historical research would be needed to help refine and complement these few insights. But if the past can inform contemporary strategies, it is first and foremost by spurring debate, reflexivity and creativity when thinking about the present. The later retains an irreducible indetermination.

\section{ACKNOWLEDGEMENTS}

This research is supported by the European Commission, H2020-ICT-2015 Programme, Grant Number 688768 'netCommons' (Network Infrastructure as Commons). The authors thank Benjamin Bayart, Laurent Chemla, Christian Paulus, Jean-Philippe Nicaise and James Stevens for generously giving their time for interviews. The authors are also grateful to Camille Paloque-Bergès, Christian Fuchs, Renato Lo Cigno and Paolo Bory for the help and for the insightful remarks of the anonymous reviewers.

\section{REFERENCES}

Acland, C. R. (2006), Residual Media, Minneapolis, MN: University of Minnesota Press.

Atton, C. (2005), An Alternative Internet: Radical Media, Politics and Creativity, Edinburgh: Edinburgh University Press.

Bailey, O. G., Cammaerts, B. and Carpentier, N. (2008), Understanding Alternative Media, Maidenhead: Open University Press and McGraw-Hill.

Benkler, Y. (2016), 'Degrees of freedom, dimensions of power', Daedalus, 145:1, pp. 18-32.

Bijker, W. E., Hughes, T. P. and Pinch, T. (1987), The Social Construction of Technological Systems, Cambridge, MA: MIT Press.

Boyle, J. (2003), 'The second enclosure movement and the construction of the public domain', Law and Contemporary Problems, 66:1\&2, pp. 33-74.

Brinson, P. (2006), 'Liberation frequency: The Free Radio movement and alternative strategies of media relations', Sociological Quarterly, 47:4, pp. 543-68.

Cardon, D. and Granjon, F. (2010), Médiactivistes, Paris: Presses de Sciences Po. Carey, J. (1989), Communication as Culture, Boston, MA: Unwin Hyman.

Couldry, N. (2015), 'Alternative media and voice', in C. Atton (ed.), The Routledge Companion to Alternative and Community Media, London: Routledge, pp. 43-53. 
Deflem, M. and Lee Dove, A. (2013), 'Historical research and social movements', in D. A. Snow, D. Della Porta, B. Klandermans and D. McAdam (eds), The Wiley-Blackwell Encyclopedia of Social and Political Movements, Malden, MA: Wiley Blackwell, pp. 560-63.

Dulong de Rosnay, M. and Musiani, F. (2016), 'Towards a (de)centralisationbased typology of peer production', tripleC: Communication, Capitalism $\mathcal{E}$ Critique, 14:1, pp. 189-207.

Enzensberger, H. M. (2003), 'Constituents of a theory of the media', in N. Wardrip-Fruin (ed.), The New Media Reader, Cambridge, MA: MIT Press, pp. 261-75.

Filippi, P. De and Tréguer, F. (2015), 'Expanding the Internet commons: The subversive potential of wireless community networks', Journal of Peer Production, 6, http://peerproduction.net/issues/issue-6-disruption-andthe-law/peer-reviewed-articles/expanding-the-internet-commons-thesubversive-potential-of-wireless-community-networks/. Accessed 17 April 2020.

Frischmann, B. M. (2007), 'Infrastructure commons in economic perspective', First Monday, 12:6, https://doi.org/10.5210/fm.v12i6.1901.

Fuchs, C. (2010), 'Alternative media as critical media', European Journal of Social Theory, 13:2, pp. 173-92.

Gabel, R. (1969), 'The early competitive era in telephone communication, 1893-1920', Law and Contemporary Problems, 34:2, pp. 340-59.

Hardin, G. (1968), 'The tragedy of the commons', Science, 162:3859, pp. 1243-48.

Hesmondhalgh, D. (2007), The Cultural Industries, London: Sage.

Hess, C. and Ostrom, E. (2007), Understanding Knowledge as a Commons: From Theory to Practice, Cambridge, MA: MIT Press.

Holcombe, A. N. (1911), Public Ownership of Telephones on the Continent of Europe, Cambridge, MA: Harvard University Press.

Kaijser, A. (1987), 'From local networks to national systems: A comparison of the emergence of electricity and telephony in Sweden', in F. Cardot (ed.), 1880-1980: Un siècle d'électricité dans le monde, Paris: Presses universitaires de France, pp. 7-22.

Kostakis, V. and Bauwens, M. (2014), Network Society and Future Scenarios for a Collaborative Economy, New York: Palgrave Macmillan.

Lasar, M. (1999), Pacifica Radio: The Rise of and Alternative Network, Philadelphia, PA: Temple University Press.

Lefebvre, T. (2011), La bataille des radios libres (1977-1981), Paris: Nouveau Monde Éditions.

Lessig, L. (1999), Code and Other Laws of Cyberspace, New York: Basic Books.

Loraux, N. (2005), 'Éloge de l'anachronisme en histoire', Espaces Temps, 87, pp. 127-39.

MacKenzie, A. (2005), 'Untangling the unwired Wi-Fi and the cultural inversion of infrastructure', Space and Culture, 8:3, pp. 269-85.

Mahoney, J. and Rueschemeyer, D. (2003), Comparative Historical Analysis in the Social Sciences, Cambridge: Cambridge University Press.

McCarthy, J. D. and Zald, M. N. (1977), 'Resource mobilization and social movements: A partial theory', American Journal of Sociology, 82:6, pp. 1212-41.

McChesney, R. W. (2007), Communication Revolution: Critical Junctures and the Future of Media, New York: New Press. 
(2013), Digital Disconnect: How Capitalism Is Turning the Internet against Democracy, New York: New Press.

Medosch, A. (2014), 'The rise of the network commons', Next Layer, 9 May, http://www.thenextlayer.org/NetworkCommons.html. Accessed 1 December 2017.

Milan, S. (2013), Social Movements and Their Technologies: Wiring Social Change, New York: Palgrave Macmillan.

Navarro, L., Baig, R., Freitag, F., Dimogerontakis, E., Tréguer, F., Dulong de Rosnay, M., Maccari, L., Micholia, P. and Antoniadis, P. (2016), 'Report on the existing community networks and their organization', netCommons, 12 October, https://www.netcommons.eu/sites/default/files/netcommons_ d1.2v1.0.pdf. Accessed 1 December 2017.

Papadimitropoulos, V. (2017), 'The politics of the commons: Reform or revolt?', tripleC: Communication, Capitalism \& Critique, 15:2, pp. 565-83.

Pickard, V. (2013), 'The air belongs to the people: The rise and fall of a postwar radio movement', Critical Studies in Media Communication, 30:4, pp. 307-26.

- (2015a), America's Battle for Media Democracy: The Triumph of Corporate Libertarianism and the Future of Media Reform, New York: Cambridge University Press.

- (2015b), 'Media activism from above and below: Lessons from the 1940s American reform movement', Journal of Information Policy, 5, pp. $109-28$.

Powell, A. (2008), 'WiFi publics: Producing community and technology', Information, Communication \& Society, 11:8, pp. 1068-88.

Preston, P. (2001), Reshaping Communications: Technology, Information and Social Change, London: Sage.

Raboy, M. (1993), 'Radio as emancipatory cultural practice', in N. Strauss and D. Mandl (eds), Radiotext(e), New York: Semiotexte, pp. 129-34.

Sandoval, M. and Fuchs, C. (2010), 'Towards a critical theory of alternative media', Telematics and Informatics, 27:2, pp. 141-50.

Tilly, C. and Tarrow, S. (2015), Contentious Politics, New York: Oxford University Press.

Tréguer, F. (2017), 'Gaps and bumps in the political history of the Internet', Internet Policy Review, 6:4, https://doi.org/10.14763/2017.4.714.

Tréguer, F., Antoniadis, P. and Söderberg, J. (2016), 'Alt. vs. Ctrl.: Editorial notes for the JoPP issue on alternative internets', Journal of Peer Production, 9, http://peerproduction.net/issues/issue-9-alternative-internets/editorialnotes/. Accessed 17 April 2020.

Tréguer, F. and Dulong de Rosnay, M. (2018), 'Community networks and political advocacy', Research Report, D1.5, ISCC-CNRS, https://halshs.archivesouvertes.fr/halshs-01792045/document. Accessed 1 December 2018.

Tréguer, F. and Trudel, D. (2019), 'From Internet access provision to digital right activism: The history of the French data network', Histoire et informatique, 21, pp. 35-48.

Trudel, D. and Tréguer, F. (2016), 'Alternative communication networks throughout history', netCommons, 30 November, https://www.netcommons.eu/ sites/default/files/d5.1_history_v1.0.pdf. Accessed 1 December 2017.

Wall, D. (2014), The Commons in History: Culture, Conflict, and Ecology, Cambridge, MA: MIT Press.

Wu, T. (2010), The Master Switch: The Rise and Fall of Information Empires, New York: Alfred A. Knopf. 


\section{SUGGESTED CITATION}

Tréguer, Félix, Trudel, Dominique and Dulong de Rosnay, Mélanie (2020), 'Learning from the history of alternative communication networks', Journal of Alternative \& Community Media, 5:1, pp. 9-26, doi: https:// doi.org/10.1386/joacm_00072_1

\section{CONTRIBUTOR DETAILS}

Félix Tréguer is associate researcher at the Center for Internet and Society (CNRS) and postdoctoral fellow at CERI-Sciences Po. His research blends political history and theory, law as well as media and technology studies to look at the political history of the Internet and computing, power practices like surveillance and censorship, the algorithmic governmentality of the public sphere and, more broadly, the digital transformation of the state and of the security field. He is a founding member of La Quadrature du Net, an advocacy group dedicated to the defence of civil rights in relation to digital technologies.

Contact: CIS CNRS, 59/61 rue Pouchet, 75849 Paris cedex 17, France.

E-mail: felix.treguer@sciencespo.fr

(D) https://orcid.org/0000-0002-0896-1303

Dominique Trudel is associate professor in media and communication at Audencia Business School in Nantes, France, and a member of the Center for Internet and Society (CNRS), the Centre de recherche interuniversitaire sur les humanités numériques (CRIHN) and the Centre de recherche Cultures Arts - Société (CELAT). His work explores the cross-genealogy of'new' media, political theory and communication studies.

Contact: Audencia Business School, 41 Boulevard de la Prairie au Duc, 44200 Nantes, France.

E-mail: dtrudel@audencia.com

(D) https://orcid.org/0000-0002-6540-006X

Mélanie Dulong de Rosnay, Ph.D. in law, is associate research professor at the French National Centre for Scientific Research (CNRS). Since 2019, she is the director of the Center for Internet and Society, a research unit of CNRS, and since 2020, she also directs a CNRS-national research network on Internet, AI and society. Her research focuses on digital commons, regulation by technology, information technology law and policy. She is a board member of Internet Policy Review and OpenEdition publishing platform.

Contact: CIS CNRS, 59/61 rue Pouchet, 75849 Paris cedex 17, France.

E-mail: melanie.dulong@cnrs.fr

(D) https://orcid.org/0000-0002-0297-7603

Mélanie Dulong de Rosnay, Dominique Trudel and Félix Tréguer have asserted their right under the Copyright, Designs and Patents Act, 1988, to be identified as the authors of this work in the format that was submitted to Intellect Ltd. 